\title{
Biotecnología en la Industria Vitivinícola en Argentina: ¿Nuevas Modalidades de Innovación en una Actividad Tradicional?*
}

\author{
Pablo Lavarello', Graciela Gutman², Sonia Filipetto ${ }^{3}$
}

\begin{abstract}
This work analyses the responses of the Argentine's Wine Industry face to the opportunities open by modern biotechnology. Since liberalization policies, Foreign Direct Investment and newcomers have reinforced competition, encouraging product differentiation strategies and innovation efforts in products and processes. At the industrial level, innovation in fermentation processes has been traditionally driven by technology incorporated into equipment and, more recently, by the adoption of new commercial yeast and enzymes developments. This paper discusses the effects of these strategy changes over wine firms knowledge base and the role played by food ingredients firms and local Science and Technology infrastructure in biotechnology adoption.
\end{abstract}

Keywords:Wine industries; technology trajectories; biotechnology; supplier-user learning processes; technology sourcing.

\section{Resumen}

Este documento estudia la respuesta de la industria vitivinícola Argentina frente a las oportunidades abiertas por las modernas biotecnologías. Las políticas de liberalización y la inversión extranjera directa se tradujeron en una mayor competencia y en la necesidad de innovaciones de producto y de proceso. A nivel industrial, la innovación en fermentación ha estado tradicionalmente determinada por la tecnología incorporada en equipos. Recientemente se observa la adopción de nuevos desarrollos de enzimas y levaduras. Este trabajo analiza los efectos de las nuevas estrategias tecnológicas sobre la base de conocimiento de las firmas y cuál es el rol de los proveedores de ingredientes y de la infraestructura de Ciencia y Tecnología en la adopción de las biotecnologías.

Palabras clave: Industria de vinos; trayectorias tecnológicas; biotecnología; aprendizaje proveedor-usuario; aprovisionamiento de tecnología.

\footnotetext{
*Este artículo se basa en los resultados del Proyecto de Investigación CEUR-CONICET “Economía Política de la innovación biotecnológica. Trayectorias y demandas tecnológicas de las industrias de la alimentación en Argentina”, el que contó con apoyo financiero del CONICET ' Dr. en Ciencias Económicas (Universidad Paris XIII), Investigador CEUR-CONICET, Profesor Universidad de Buenos Aires (UBA), Saavedra 15 6to p., CABA (CI 083ACA),Argentina.Tel.-Fax (54 II) 4952 4222, plavarello@conicet.gov.ar ${ }^{2}$ Economista, Investigadora Principal del CONICET,Vice-Directora CEUR-CONICET, Saavedra 15 6to p., CABA (CI083ACA), Argentina. Tel.-Fax (54 I I) 4952 4222, gutman.graciela@conicet.gov.ar

${ }^{3}$ Lic en Economia (UBA), Becaria Doctoral CEUR-CONICET, Saavedra I5 6to p., CABA (CI083ACA), Argentina. Tel.-Fax (54 II) 4952 4222, sonia.filipetto@gmail.com
} 


\section{Introducción}

Este documento analiza la respuesta de la industria vitivinícola Argentina frente a las oportunidades abiertas por las modernas biotecnologías. Desde las dos últimas décadas, la industria mundial de vinos se enfrenta a la entrada de nuevos países exportadores que disputan el liderazgo de los productores tradicionales a partir de estrategias basadas en el control de portafolios de marcas y la creciente globalización de los grandes grupos de los países productores tradicionales (Rastoin, 2000; Rastoin, et al, 2006; Lavarello y Filipetto, 20I0). En este contexto de mayor competencia, las empresas líderes a nivel mundial llevan adelante estrategias de diferenciación de productos a partir de portafolios de marcas o el desarrollo de uvas de alta calidad enológica. Estas estrategias de marketing y de desarrollo a nivel primario requieren, en la etapa industrial, un conjunto de innovaciones fuertemente dependientes de los avances recientes en la biotecnología.

Argentina se encuentra entre el conjunto de nuevos jugadores, siendo el quinto productor mundial de vino con el $7 \%$ de la producción, y el séptimo exportador en volumen en el año 2008 (OIV, 2008). La Argentina no se encuentra ajena a la mayor presión competitiva y a las estrategias innovativas de las empresas líderes. Hasta la década de los ' 90 , el desarrollo de la industria vitivinícola en Argentina estuvo asociado a la fabricación y comercialización de vinos para el mercado nacional / orientado mayoritariamente a la producción de vino de mesa) y a la exportación de mosto de uva. A partir de la segunda mitad de los años 90 , la entrada de grupos multinacionales y la respuesta de las empresas locales resultó en una mayor heterogeneidad de firmas. Este proceso se tradujo en una mayor presión competitiva y en una creciente heterogeneidad de estrategias.

La mayor presión competitiva, la exigencia de avanzar hacia estrategias de calidad y de lanzamiento de nuevas variedades adaptadas a condiciones locales, resultó en la adopción de nuevas técnicas. La literatura existente focaliza su análisis en la adopción de tecnología "incorporada" en maquinaria y a innovaciones en la organización de producción agrícola(Gross Fuentes, 1999; Bocco, et al, 2009).

En la literatura se encuentra menos explorada la dinámica tecnológica de las etapas industriales y en particular, el rol jugado por la biotecnología en la introducción de ingredientes y la mejora de los procesos de fermentación que ello trae aparejado. En los últimos 20 años se difundieron en el país una amplia gama de proveedores internacionales de levaduras, enzimas y bacterias con fuerte impacto en dichos procesos productivos. Estos nuevos desarrollos han sido en gran medida posibles gracias al mejor conocimiento de los microrganismos y la capacidad de la biología molecular de mejorar la selección de los mismos. El objetivo general del artículo es analizar la respuesta de la industria vitivinícola argentina a los nuevos desafíos abiertos por la moderna biotecnología, interrogándonos sobre la capacidad de la industria vitivinícola, junto a los proveedores y a la infraestructura local de Ciencia y Técnica, para transformar estas oportunidades en desarrollos y/o mejoras de procesos con éxito comercial. Los objetivos particulares son analizar por un lado, (i) cómo estos desarrollos impactan en las trayectorias tecnológicas previas de distintos tipos de empresas, en las que los saberes artesanales de los enólogos pueden llegar a jugar roles diferentes en la selección de las tecnologías en el sector, y por el otro, (ii) el rol de los proveedores de ingredientes en la adopción de las nuevas tecnologías y si dan lugar a aprendizajes interactivos en el marco del sistema nacional de innovación.

Metodología y fuentes de información: La metodología empleada a fin de responder estos interrogantes se basó en el estudio de casos a partir de entrevistas en profundidad a tres empresas líderes a nivel local y a los representantes locales de tres empresas proveedoras globales de ingredientes biotecnológicos. Se seleccionó a tal fin: una filial de la Empresa Multinacional francesa Moët \& Chandon, un grupo familiar local, las Bodegas Zuccardi, y una gran cooperativa local, FECOVITA, con larga trayectoria en la industria de vinos comunes de mesa.

El artículo se organiza de la siguiente forma. En la sección I se presentan la problemática teórico-empírica planteada, sus antecedentes y la justificación del estudio. En la sección 2 se analiza la evolución tecnológica en la industria del vino a nivel internacional, a fin de señalar las dinámicas tecnológicas generales en las que se inscribe la problemática del artículo. En la sección 3 se identifican los casos que se van a estudiar a partir de un análisis de la estructura de mercado y en las estrategias de las empresas locales. En la sección 4 se presentan los principales 
resultados de las entrevistas a las empresas usuarias identificando sus estrategias y capacidades tecnológicas; en la sección 5 se presentan los resultados referidos a las modalidades de interacción y de apropiación de la tecnología entre proveedores, usuarios y la infraestructura de CyT local. Finalmente, en las conclusiones, se retoman las principales evidencias del estudio en función de los objetivos del artículo.

\section{Antecedentes y Marco Conceptual}

Diversos estudios plantean una tensión entre la codificación de los procesos productivos y la persistencia/ recreación de conocimientos tácitos y específicos en la industria alimentaria (Bye y Mounier, 1981; Bye, 1995; Nicolas y Hy, 1995; Lavarello 200I). Esta problemática ha sido también desarrollada en términos teóricos por una extensa literatura sobre la micro dinámica del cambio tecnológico, en la que las especificidades de los conocimientos tecnológicos resultantes de aprendizajes por la experiencia y la emergencia de nuevos conocimientos genéricos dan lugar a una reestructuración de las industrias (Dosi, 1984; Antonelli, 1999). En el marco de un estudio realizado por la OCDE a fines de los años 70 , se planteaba que esta tensión en realidad obedece a la trayectoria histórica de la química y su capacidad para transformar las actividades artesanales en procesos en continuo (Chesnais, 1979).

En el caso de las actividades vitivinícolas, ciertos trabajos estudian esta tensión entre las nueva técnicas agronómicas adoptadas en la etapa agrícola y los saberes tácitos de los productores (Bocco, et al, 2007; Bell y Giuliani, 2007). Un aspecto que refuerza esta tensión, menos explorado en la literatura, es el rol que han jugado los avances recientes en la biología molecular en las tecnologías de fermentación. En la industria vitivinícola, el cambio tecnológico venía determinando por su incorporación en bienes de capital y por los saberes artesanales de los enólogos en la selección de las cepas de levaduras utilizadas en la fermentación. No obstante, la acumulación de capital exige avanzar en la industrialización de estos procesos a fin de asegurar, por un lado, la producción en gran escala y por el otro, reducir los tiempos de rotación del capital. La biotecnología abre nuevas oportunidades en este sentido, a partir de la identificación, selección y eventualmente modificación de las levaduras y bacterias que cumplan con estos objetivos. Esto requiere la ampliación de las capacidades y de los conocimientos en biología molecular que no todas las industrias (y empresas) tienen posibilidades de integrar.

En este contexto, cabe interrogarse, por un lado, qué grado de complementariedad tienen las nuevas tecnologías altamente codificadas, con las fuentes de conocimiento tácito previamente señaladas, $y$, por el otro, si la oportunidades mayores de las biotecnologías se traducen en el desarrollo de capacidades endógenas por parte de las empresas vitivinícolas, a partir de la interacción con los proveedores y de vinculaciones con la infraestructura local de CyT. Interacciones que, de acuerdo con la literatura de sistemas nacionales de innovación, tienen potencialidades de generar aprendizajes tecnológicos proveedor-usuario y recombinación de conocimientos codificados en el espacio nacional (Antonelli, 1999; Lundvall, 1992). La respuesta a estos interrogantes es importante para el diseño de políticas tecnológicas que busquen reforzar las externalidades localizadas, generando efectos sistémicos sobre la organización y competitividad de la industria.

\section{Trayectoria Tecnológica en la Industria de Vinos a Nivel Internacional: Oportunidades Científicas y Proveedores Tecnológicos}

La fermentación del vino se compone de una secuencia de técnicas que involucran procesos físicos - de molienda y prensado de la materia prima-y biológicos - fermentación, estabilización y conservación o añejamiento (en barricas) ${ }^{4}$. La trayectoria tradicional de la industria vitivinícola se asocia a mejoras incrementales en a partir de los saberes tácitos incorporados en la experiencia de los enólogos. Estos profesionales juegan un rol clave en la selección de distintas cepas y variedades así como en fuentes externas como es la adquisición de maquinarias y equipos.

Como se señaló en la introducción, la mayor competencia en los mercados vitivinícolas promueve procesos de diferenciación de productos, los que incluyen la introducción de nuevas variedades de uva en la etapa primaria. No obstante, estas innovaciones deben ser complementadas

${ }^{4}$ Ver M. Combina (2007) "La industria vitivinícola: la biotecnología en Enología” Documento preparado en el marco del proyecto CEURCONICET ““‘Economía Política de la Innovación Biotecnológica”. 
por mejoras y adaptaciones en los procesos fermentación de la uva, sin las cuales no sería viable económicamente una estrategia basada en la diferenciación de productos y el mantenimiento de la calidad de los productos existentes. El sostenimiento de calidades homogéneas de una campaña agrícola a la otra, la reducción de tiempos de fermentación y el control de desarrollos microbianos no deseados constituyen problemas técno-económicos cruciales en este tipo de industrias.

Por ello, las innovaciones en levaduras, bacterias y enzimas posibilitan mejorar la calidad sostenida en el tiempo y responder a las crecientes exigencias de diferenciación. Las innovaciones en nuevas levaduras posibilitan controlar la acción de procesos de fermentación espontánea, con efectos sobre la calidad que son altamente impredecibles. No obstante, existen segmentos industriales cuya estrategia se basa en la renovación de sabores bajo condiciones espontáneas de desarrollo de microrganismos durante la fermentación. Este es el caso las bodegas boutique que optan por tecnologías artesanales, asumiendo los riesgos de la variabilidad del producto. En los segmentos indus- triales intensivos en escala, la lógica de acumulación exige procesos rápidos y confiables de fermentación, esenciales para lograr vinos con gustos consistentes y calidad predecible, reduciendo al mismo tiempo, los tiempos de rotación del capital. En estos casos se recurre a cepas de levaduras comerciales seleccionadas (levaduras de la especie S. cerevisiae) y al desarrollo de enzimas (Ver recuadro $\left.\mathrm{N}^{\circ} \mathrm{I}\right)$.

De esta forma, se asiste a una tensión entre la trayectoria tecnológica preexistente, asociada a una base estrictamente empírica limitada por el desconocimiento de las características a nivel molecular de los microorganismos y de su metabolismo, y los avances de la biología molecular, con el mayor conocimiento de los procesos que rigen las transformaciones en el proceso de fermentación.

Existen técnicas diferentes a las basadas en el ADN recombinante que utilizan la biología molecular para la identificación, diferenciación y seguimiento de los microorganismos involucrados en los procesos fermentativos, apoyadas en técnicas convencionales de selección (Recuadro $\mathrm{N}^{\circ} \mathrm{I}$ ).

\section{Recuadro $\mathrm{N}^{\mathbf{0}} 1$ : Oportunidades de la biotecnologia en la industria vitivinícola}

Durante los últimos 20 años, como resultado de la difusión del nuevo paradigma tecnológico, el proceso de vinificación se han transformado, el enólogo necesita herramientas eficaces para conseguir los vinos que ha planificado. Los avances biotecnológicos en enología permiten resolver tres tipos de problemas técnicos en el proceso de fermentación (Combina, 2007):

$>$ La selección de levaduras y bacterias lácticas: la levadura es la responsable de la mayor parte de la transformación de azúcar del mosto de la uva en etanol durante la primera fermentación La selección de levaduras permite aumentar la calidad y consistencia del vino. Durante la elaboración del vino, se realiza una segunda fermentación a partir de bacterias lácticas. Por estos motivos las bodegas utilizan en forma creciente levaduras y bacterias comerciales.

$>$ El mejoramiento del proceso de fermentación a partir del desarrollo de enzimas La I+D en enzimas busca reducir los tiempos de producción y lograr mejores características del producto final. Al acelerar los procesos de clarificación durante la fermentación y la maduración, las enzimas aumentan la rentabilidad, y al mejorar las características de color y aroma durante la maceración permiten lograr una diferenciación de producto consistente en el tiempo.

- Desarrollo de bio-controladores para evitar la formación de compuestos tóxicos y defectos en los vinos: Existen levaduras que pueden inhibir el desarrollo de ciertos microorganismos en el mosto del vino que generan defectos en el gusto del vino o que justifican la aplicación de barreras paraarancelarias en la Unión Europea.

Recuadro Nº I: Oportunidades de la Biotecnología en la Industria Vitivinícola 
Frente a las nuevas oportunidades que abre la biotecnología en industrias basadas en la fermentación, como es el caso de la fabricación de vinos, no se evidencia una participación importante de la industria vitivinícola en la adopción de estas biotenologías técnicas. Hacia inicios de la presente década, sólo dos grandes empresas multinacionales francesas -Pernod Ricard y LVMH Chandon- contaban con patentes biotecnológicas. Estas empresas no tenían más de diez patentes en estas disciplinas, contrastando con empresas multinacionales agroalimentarias como Nestlé que cuenta con varios cientos de patentes biotecnológicas. La situación no ha cambiado en los últimos años. Entre las diez primeras empresas del ranking de ventas en la industria vitivinícola mundial, solo cinco habían depositado patentes en Estados Unidos entre los años 2001 y I 2009.

Que exista un bajo grado de involucramiento de la industria vitivinícola en estos desarrollos no significa que no se utilicen levaduras o enzimas seleccionadas a partir de técnicas biotecnológicas. De hecho, la difusión de la moderna biotecnología es controlada por un conjunto de empresas globales proveedoras de ingredientes. Existe alrededor de una decena de empresas de ingredientes alimentarios con capacidades biotecnológicas endógenas, que diversifican sus productos en varias aplicaciones alimentarias y no alimentarias, entre las cuales las industrias de vitivinicultura son sólo uno de sus mercados relevantes.

- Los proveedores internacionales intervienen en los tres segmentos principales del mercado de ingredientes, según cual sea el microorganismo involucrado: levaduras, enzimas o bacterias lácticas. En el segmento de levaduras, la empresa canadiense Lallemand es la principal productora la que, a partir del control de los activos de producción, ocupa un lugar nodal en la articulación de una red de aprovisionamiento internacional en la cual coexiste con un conjunto de empresas que le delegan la producción, y mantienen internamente actividades de I+D y distribución (Laffort ${ }^{5}$, Mauri ${ }^{6}$ y $\mathrm{AEB}^{7}$ ).
- En el segmento de enzimas para vinos, la empresa que domina la producción es la multinacional Novozymes, compartiendo el mercado con la empresa DSM, AB de Associated British Foods y Pascal Biotech (esta última, parte del grupo AEB). El resto de las empresas llevan adelante algunas etapas de I+D y comercializan enzimas, delegando la producción a Novozymes y DSM.

- En el segmento de bacterias lácticas, de menor expansión que los dos previos, Christian Hansen es el principal productor, compartiendo el mercado con Lallemand y Laffort.

Todas las empresas cuentan con laboratorios de $I+D$ en biología molecular, a partir de los cuales identifican los microorganismos o proteínas utilizados en la fermentación del vino. Las técnicas biotecnológicas utilizadas no se basan en tecnologías del ADN recombinante como la ingeniería genética, sino en la utilización de técnicas basadas en ADN para identificar y optimizar los microrganismos. Estas técnicas no implican modificación de los organismos sino que preferentemente aceleran los tiempos de $I+D$ vis a vis las técnicas extractivas tradicionales.

Es interesante notar que la organización de estos grupos asume la forma de una red de empresas. Son pocas las empresas que integran las plantas de producción (Lallemand para levaduras y bacterias, Novo y DSM en enzimas). La gran mayoría de empresas proveedoras externalizan la producción en estas empresas integradas que han acumulado experiencia y escala en la fabricación . Por su parte, la I+D se organiza a partir de una densa trama de acuerdos de cooperación con laboratorios públicos a nivel mundial. Esto les permite ampliar sus bibliotecas de microorganismos, acelerar los procesos de aprendizaje y disminuir sensiblemente los costos fijos de la I+D.

En resumen, la irrupción de las modernas biotecnologías resulta en una ampliación y cambio en la composición de la base de conocimientos requeridos para el desarrollo potencial de la industria. Esto requiere conocimientos que combinen por un lado, aprendizajes por experiencia previa en bioprocesos,

\footnotetext{
${ }^{5}$ Empresa francesa que se especializa en ingredientes para vinos blancos concentra sus actividades en actividades de investigación y comercialización, externalizando la producción en otras empresas (Lallemand en levaduras y NOVOZyMES en enzimas). Su competencia principal se encuentra en las actividades de I\&D, a partir de su laboratorio SARCO en Bourdeaux en el cual lleva adelante junto a otras empresas y Universidades proyectos aplicados a levaduras, bacterias y enzimas. ${ }^{6}$ Mauri Yeast Australia es la división de levaduras de la multinacional inglesa Associated British Foods cuyas actividades se localizan en Australia. Con 4400 empleados, esta división se especializa en levaduras para vinos, cervezas y sake - conocida en el primer caso por su marca Maurivin-. Cuenta con competencias en microbiología, fermentación y enología. ${ }^{7} E$ E Grupo italiano AEB se especializa en la investigación y en la aplicación de los tratamientos de procesos que conciernen la bioquímica y la higiene ambiental. Si bien su principal actividad se centra en detergentes y productos de limpieza industriales para las industrias alimenticias, también desarrollan y producen ingredientes a partir de biotecnología aplicada a la vinificación, coadyuvantes de fermentación y productos para la estabilización del vino y de la cerveza.
}

ISSN: 07I8-2724. (http://www.jotmi.org) 
enología y bromatología; por el otro, el acceso a conocimientos genéricos y codificados de modernas técnicas de biología molecular. Las industrias usuarias no muestran un involucramiento importante en estas tecnologías. Son los proveedores de ingredientes los que asumen el rol difusión de los nuevos conocimientos en la industria. En las secciones siguientes analizaremos cómo responde la industria vitivinícola argentina a lo nuevos desafíos abiertos por la creciente presión competitiva y la irrupción de los nuevos conocimientos científicos.

3. Estructura de la industria vitivinícola en Argentina: identificación y presentación de los casos de estudio seleccionados.

Previo a considerar la adopción de nuevas tecnologías genéricas por parte de las empresas del sector, analizamos la estructura industrial de la industria vitivinícola local a fin de contextualizar la selección de los casos de estudio realizadas en este trabajo.

\section{I. Estructura de la industria}

La estructura de mercado de la industria de vinos en Argentina es significativamente más concentrada que la de los países europeos. Esto se explica porque esta industria ha sido durante varias décadas terreno de expansión de Grupos Económicos (Ver Cuadro $N^{\circ}$ I). A ello se agrega la entrada durante los años ' 90 de empresas multinacionales. Luego, las ocho primeras empresas alcanzan cerca del $60 \%$ de las ventas, mostrando una estructura del mercado estratificada, con un segmento de grandes grupos y filiales de empresas multinacionales que dominan el mercado integrando marcas y diversas producciones, y una multiplicidad de empresas con participaciones menores.

\begin{tabular}{|l|c|c|}
\hline \multicolumn{2}{|c|}{ Grupos/empresas } & \multicolumn{2}{|c|}{} \\
\cline { 2 - 3 } & Ventas & Parte Mercado (\%) \\
\hline Grupo Peñaflor (Argentina) & 1024,9 & \\
\hline - Bodegas y Viñedos Peñaflor & 637,0 & \\
\hline - Bodegas Esmeralda & 212,9 & \\
\hline - Bodegas y Viñedos Andinos & 175,0 & $\mathbf{8 , 9}$ \\
\hline Grupo Catena (Argentina) & $\mathbf{3 7 0 , 0}$ & $\mathbf{8 , 6}$ \\
\hline Bodegas Chandon (Francia) & $\mathbf{3 5 6 , 0}$ & $\mathbf{4 , 2}$ \\
\hline Pernod Ricard (Francia) & $\mathbf{1 7 6 , 0}$ & $\mathbf{3 , 2}$ \\
\hline Marubeni (Japón) & $\mathbf{1 3 3 , 0}$ & \\
\hline - Viñas Argentinas & 133,0 & $\mathbf{3 , 0}$ \\
\hline Gernot Swarovsky (Austria) & $\mathbf{1 2 5 , 0}$ & \\
\hline - Bodegas Norton & 125,0 & $\mathbf{3 , 1}$ \\
\hline Fecovita (Argentina) & $\mathbf{1 3 0 , 0}$ & $\mathbf{2 , 6}$ \\
\hline Diageo (GB) & $\mathbf{1 1 0 , 0}$ & \\
\hline Cinba & 110,0 & $\mathbf{2 , 7}$ \\
\hline ByV Lopez (Argentina) & $\mathbf{1 1 1 , 0}$ & $\mathbf{2 , 4}$ \\
\hline La Riojana Coop. Vit. (Argentina) & $\mathbf{1 0 0 , 0}$ & $\mathbf{2 , 8}$ \\
\hline RPB (Argentina) & $\mathbf{1 1 5 , 5}$ & $\mathbf{2 , 4}$ \\
\hline Valentín Bianchi (Argentina) & $\mathbf{9 9 , 0}$ & $\mathbf{2 9 , 4}$ \\
\hline Bodegas Zuccardi (Argentina) & $\mathbf{4 1 5 4 , 4}$ & \\
\hline Subtotal & & \\
\hline Total industria & \\
\hline
\end{tabular}

Cuadro $N^{\circ}$ I: Principales empresas del complejo vitivinícola en Argentina. /Fuente: elaboración propia en base a Prensa Económica y Mercado 
Entre los capitales de origen extranjero es de destacar la presencia demultinacionalesfrancesasquesehan expandido gracias a una estrategia de desarrollo de marcas locales. Las empresas de EEUU no entran a disputar el mercado local o integrar la producción, sino que realizan alianzas con empresas locales. Paralelamente, existen grupos locales con estrategias de diferenciación y especialización en vinos de alta gama que combinan una importante presencia en el mercado interno con la inserción en redes globales de aprovisionamiento de traders internacionales o de marcas globales. Estas empresas frecuentemente acompañan las estrategias productivas con la apertura de su capital a fondos de inversión extranjeros. El capital proveniente de Estados Unidos prioriza modalidades de entrada al mercado local menos visibles, con predominio financiero y baja inmovilización de capital.

\subsection{Selección de los casos y metodología}

A fin de desarrollar los objetivos del estudio y responder a la problemática planteada en la sección 2 , se diseñaron entrevistas semi-estructuradas a tres empresas usuarias y a tres empresas proveedoras de ingredientes. Las entrevistas fueron realizadas, entre marzo del año 2007 y septiembre del año 2008, a los gerentes de I+D de las empresas vitivinícolas y a los responsables de los departamentos de adaptación tecnológica de las proveedoras globales de ingredientes.

Teniendo en cuenta las consideraciones generales sobre la estructura de la industria locales se seleccionaron como caso de estudios: la filial de la EMN francesa Moët \& Chandon, la cooperativa local FECOVITA y el grupo familiar Zuccardi. Estas tres empresas alcanzan al $14 \%$ de la producción local y el 13,6\% de las exportaciones, y son representativas de las formas de organización y orígenes de capital prevalecientes en la industria local.

Estas empresas llevan adelante estrategias productivas y comerciales diferentes. Mientras que Chandon se orienta al mercado interno e internacional a partir de una estrategia de especialización por producto y marca (vinos premium y semi premium), Fecovita combina la explotación del segmento de vinos de bajo costo con la inserción en cadenas de aprovisionamiento flexible de empresas multinacionales de Estados Unidos con vinos de media/alta gama de calidad. Por su parte la familia Zuccardi es representativa de un conjunto de empresas especializadas que disputan el mercado a las grandes empresas diversificadas. Esta estrategia se basa en la búsqueda de nichos de producto con vinos de alta gama en el mercado internacional (orgánicos), desarrollando su propia marca, complementando esta actividad con otras líneas de productos para el mercado interno. En función de estas diferencias, cabe esperar que por un lado, se pueda dilucidar si la tensión entre los conocimientos específicos y los genéricos es mayor en los casos de empresas locales con una mayor propensión a apoyarse en la experiencia para sus innovaciones (objetivo particular i), y por el otro, cuales son las modalidades de vinculación entre las empresas, los proveedores y la infraestructura de ciencia y tecnología (objetivo particular ii)

En forma complementaria al análisis de las industrias usuarias, se entrevistó a tres empresas globales de proveedores de ingredientes para la industria vitivinícola con presencia en Argentina. En tanto mercado en expansión, la industria vitivinícola argentina constituye un destino de interés para los principales proveedores internacionales. Las estrategias de expansión de estas empresas se basan en dos factores contrapuestos. Por un lado, la valorización de los desarrollos obtenidos en los países centrales, a partir de la exportación de nuevas cepas de levaduras comerciales, bacterias y enzimas. Por el otro, y en sentido inverso, la apropiación de cepas de microorganismos desarrollados localmente por instituciones públicas, que luego adaptan en sus laboratorios centrales para ser comercializadas a partir de una estrategia global.

El análisis de los tres casos en los que su presencia local excede a la actividad comercial, permite confirmar estas apreciaciones generales.

Lallemand: Esta empresa controla el $70 \%$ de la producción de levaduras y bacterias para vinos a nivel mundial. Cuenta con 17 plantas, de las cuales dos están dedicadas a la producción de levadura para vinos localizadas en $\mathrm{Ca}$ nadá y en Dinamarca, y una a la producción de bacterias, localizada en Francia. La empresa generó capacidades en biología molecular, que centraliza en Canadá, Dinamarca y Francia. Estas capacidades se complementan con colaboraciones con varias universidades y centros de investigación de su país de origen e internacionales. Entre ellas se destacan los acuerdos de cooperación con el INRA y la Universidad de Nantes en Francia, y con el INTA en Argentina. Si bien la empresa no produce ni realiza actividades de I+D en Argentina, lleva adelante en el país una estrategia de exploración de potenciales cepas. 
AEB: El grupo dispone de laboratorios propios de I+D situados en cada establecimiento productivo, coordinados por el laboratorio principal con sede en Brescia, Italia. Cuenta con un laboratorio de aplicaciones tecnológicas en Mendoza, que adapta las formulaciones a los clientes locales. Este laboratorio experimenta nuevos productos en forma conjunta con la sede en Brescia, en donde se centraliza las capacidades de I+D.

Christian Hansen: desarrolla y produce ingredientes naturales para las industrias agroalimentarias $y$ farmacéuticas así como diagnósticos para alergias, y productos biotecnológicos para los mercados de salud humana y , animal y para producciones industriales. Sus competencias centrales son las tecnologías defermentación y la fisiología microbiológica. La investigación esta centralizada en la sede de su casa matriz, en Dinamarca y posee cuatro centros de desarrollo (en Dinamarca., EEUU, Francia y Alemania). En Argentina instaló un laboratorio de desarrollo de aplicaciones (adaptación a clientes específicos) a partir del cual tiene capacidades para realizar convenios con empresas e institutos locales para desarrollos conjuntos, tal como lo ha hecho exitosamente en el caso de prebióticos lácteos. Su especialización en la cadena vitivinícola es en bacterias lácticas, que aún no se han difundido masivamente en la industria.

Como se desprende del análisis, si bien casi todas las empresas proveedoras de ingredientes abrieron oficinas de comercialización de sus productos desde los años ' 90 , ninguna de ellas realiza actividades de fabricación ni de I+D local. Argentina ocupa un lugar secundario en la red de generación de tecnología a nivel global. No obstante, la creciente importancia de la industria usaría local y la existencia de una importante infraestructura de Ciencia y Técnica ha justificado la instalación de laboratorios de aplicación/adaptación tecnológica y la realización de acuerdos de colaboración con laboratorios locales.

\section{Estrategias tecnológicas de las empresas vitivinícolas argentinas: el rol de los usuarios}

La heterogeneidad de tamaños, estructuras organizacionales y estrategias en la industria vitivinícola se traduce en diferentes estrategias de innovación. Las tres empresas analizadas han incorporado (y en algunos casos desarrollado) innovaciones asociadas a la selección de nuevas levaduras $u$ otros ingredientes en sus procesos durante los últimos años. Su involucramiento en el desarrollo de los mismos será diferenciado en función de su posicionamiento estratégico en el mercado.
Chandon (LVMH): En la medida que el mix de productos de la empresa se inserta en una especialización regional/ mundial exportando productos con marcas reconocidas, su estrategia innovativa se centra en fidelizar su clientela asegurando la calidad a lo largo de la cadena de valor. Esto exige esfuerzos de selección de la materia prima y aseguramiento de calidad previsible y consistente de sus vinos. El mantenimiento de la reputación de la marca le exige jerarquizar la calidad como objetivo prioritario de su actividad innovativa. En función de ello la empresa, si bien no utiliza levaduras ni enzimas modificadas genéticamente, cuenta con capacidades en su casa matriz en biología molecular a fin de seleccionar los microrganismos que permitan asegurar la estabilidad del proceso de fermentación y asegurar la calidad.

Respecto a las fuentes de conocimiento, la filial local no realiza actividades de $I+D$, sino de experimentación en las ultimas etapas del desarrollo del producto. La tecnología proviene de su casa matriz, en donde se centraliza la formación del personal (LVMH Chandon University). La selección de levaduras, a partir de los laboratorios de I+D en la casa matriz, se orienta fundamentalmente hacia mejoras en la calidad del proceso de fermentación. Combinan técnicas tradicionales con herramientas de biología molecular. Si bien la empresa desarrolla los ingredientes en su casa matriz, existe una estrecha articulación con los proveedores. Tal es el caso del acuerdo de LVMH Chandon con Chrs Hansen para optimizar el proceso de fermentación partir del desarrollo de levaduras y bacterias. También existen acuerdos de Chrs Hansen en el desarrollo de bacterias. Es de destacar asimismo la vinculación con Laffort y Lallemand (fermentos alcohólicos, levaduras de espumantes y enzimas).

Fecovita: La empresa se caracteriza por un bajo esfuerzo en actividades de I+D. Las capacidades innovativas internas se basan en conocimientos tácitos incorporados en la experiencia de los cinco profesionales del laboratorio de enología de la empresa (dos enólogos y tres asistentes técnicos) y de los seis técnicos en producción, sobre un personal de 500 empleados. Luego, la empresa realiza un bajo esfuerzo tecnológico en conocimientos codificados y especializa su base de conocimientos en los saberes tácitos de los enólogos. Las innovaciones de producto han estado asociadas a los aprendizajes realizados por estos profesionales y a los clientes internacionales que son los que determinan las características de diferenciación (por ejemplo: gustos menos asociados al roble y más a sabores frutales). 
Entre las fuentes tecnológicas, se destacan los proveedores de maquinaria como los principales vectores del cambio tecnológico en la empresa, dejando en un segundo plano a los proveedores de ingredientes. Predominan los grandes proveedores, con los que mantienen relaciones comerciales. No existe vinculación formal con los mismos más allá de la comercial, en la cual FECOVITA elige entre las alternativas existentes sin participar en procesos innovativos conjuntos con los proveedores. A pesar del rol secundario de los ingredientes en la estrategia tecnológica, la introducción reciente de nuevas variedades de levadura resultó central para el éxito del reposicionamiento estratégico del grupo en productos de alta gama. En este caso la empresa se vinculó con la infraestructura local de Ciencia y Tecnología para el desarrollo de cepas de levaduras adaptadas a las condiciones específicas locales (en cuanto a desarrollo de fagos) ${ }^{8}$.

Zuccardi: Su estrategia comprende la diferenciación de un nicho de vinos orgánicos, valorizando sus marcas a nivel internacional. El $30 \%$ de sus viñedos son orgánicos. Exportan el $60 \%$ de su producción, en productos de gama media ( 10 U\$S la botella) y alta (mas de 45 U\$S la boteIla). Esta estrategia requiere un conjunto de esfuerzos a lo largo de la cadena de valor que va desde las condiciones de producción en la finca hasta el desarrollo de levaduras orgánicas, pasando por estrictos controles de calidad en la etapa de producción. Para lo cual, si bien utilizan los mismos equipos e instalaciones que para el segmento de vinos semi-premium y premium convencional, extreman las medidas de calidad en la limpieza. Este conjunto de esfuerzos les permitió obtener certificación nacional e internacional de vino orgánico mediante auditorias nacionales homologadas internacionalmente.

En términos generales, la tecnología es adoptada por la empresa a partir de proveedores de insumos y equipamiento. Al igual que en el caso de FECOVITA, los proveedores son los que marcan el ritmo y la dirección de la innovación, en el marco de una constante renovación de insumos, siguiendo la tendencia a nivel mundial. Los vínculos son en todos los casos comerciales y no realizan ningún tipo de convenio de I+D. Si bien la trayectoria sigue siendo determinada por los proveedores, la empresa realiza esfuerzos tecnológicos y se orienta gradualmente a la absorción de capacidades y conocimientos codificados en biología molecular?. El posicionamiento en un nicho orgánico le exigió emprender un desarrollo de variedades de uva y de levaduras para el proceso de fermentación utilizando técnicas basadas en biología molecular.

Cuentan con un laboratorio de microbiología, el cual sirvió de base para un desarrollo puntual de levadura, que luego ha sido multiplicada internamente. El proyecto fue llevado adelante a partir de la consultoría de un $\mathrm{PhD}$ en Microbiología traído de Francia, quien confeccionó un procedimiento que luego fue implementado por la empresa.

La empresa también ha realizado acuerdos de vinculación formal con los institutos tecnológicos locales, aunque en ciertos casos resultaron frustrados por problemas de apropiación del conocimiento generado. Ante el temor de fuga de información y apropiación por parte de la competencia, decidieron no avanzar en posteriores vinculaciones con la infraestructura local de Ciencia y Técnica y prefirieron combinar la integración y la consultoría internacional.

En resumen, la utilización de levaduras y enzimas es mayor a medida que la empresa se orienta a estrategias más activas de mejoras en calidad reforzando marcas de gama media y/o diferenciación de productos en nichos de alta gama. Este es claramente el caso de la filial de la empresa multinacional Chandon. Las empresas nacionales, recurren a fuentes internas de conocimiento basadas en la experiencia de los enólogos. Sin embargo, se evidencia el desarrollo de capacidades locales en microbiología cuando estas empresas han decidido avanzar en estrategias de diferenciación de productos. En estos casos las empresas llevan adelante acuerdos puntuales de consultoría con científicos extranjeros o con instituciones locales. Las alianzas con proveedores no tienen por objeto desarrollos conjuntos, aunque existen aprendizajes usuario-proveedor informales y limitados como subproducto de las relaciones comerciales. Estos aspectos se analizan en la sección siguiente.

\footnotetext{
${ }^{8}$ Se destaca la levadura AC INTA 0I que permitió una mejora sensible en la calidad de una nueva variedad Malbec en el año 2003, producto que permitió a la empresa obtener un premio (LAVINANDINA 2003). La producción local de esta levadura fue discontinuada en el año 2003. Posteriormente, el proyecto fue retomado por una empresa multinacional. ${ }^{9}$ En la etapa primaria recurrieron a marcadores moleculares para mejorar la eficiencia en la cruza tradicional. En el proceso de fermentación, desarrollaron una cepa de levadura idónea y sin modificación genética. Para ello, realizaron validaciones mediante técnicas de PCR. El desarrollo propio, posibilitó lograr una levadura basada en un pool de cepas que permite un importante ahorro de costos en comparación con las levaduras de una sola cepa.
}

ISSN: 07I8-2724. (http://www.jotmi.org) 


\section{Vinculaciones en el sistema nacional de innovación}

Una vez delineadas las estrategias tecnológicas de las industrias usuarias, analizamos las formas de interacción entre éstas, los proveedores de ingredientes y la infraestructura de ciencia y tecnología local. Es de particular interés indagar sobre la capacidad de respuesta del sistema nacional de innovación de responder a los desafíos abiertos a la industria frente al creciente peso de los proveedores internacionales de ingredientes.

\section{I. Modalidades de vinculación entre proveedores y usuarios}

Las casas matrices de las empresas multinacionales vitivinícolas, como lo ilustra el caso de LVMH Chandon, mantienen una estrecha colaboración con los proveedores de ingredientes. Se evidencia una modalidad particular de división del trabajo en el desarrollo y producción de los ingredientes, en la cual la gran empresa usuaria lleva adelante la fase de diseño inicial y, la empresa proveedora se encarga de la transferencia y fabricación a escala industrial de los mismos. La casa matriz identifica y caracteriza las cepas de levaduras a partir de capacidades propias en microbiología y los proveedores intervienen en el escalado y fabricación de la levadura; luego de ser aprobada para su comercialización, es introducida en el mercado por la usuaria. De esta forma, la empresa usuaria desarrolla capacidades propias en la identificación de los problemas tecno-económicos, quedando las empresas proveedoras encargadas de la resolución de los mismos. Esta vinculación se manifiesta sólo a nivel internacional, la filial local recibe los ingredientes desarrollados a través de su casa matriz.

Por su parte, las empresas usuarias locales no priorizan relaciones formales de $I+D$ con sus proveedores internacionales. Las pequeñas empresas, entre ellas las bodegas boutique, optan por los fermentos naturales y no compran fermentos comerciales, asumiendo los mayores riesgos en los procesos. Las empresas nacionales más grandes se encuentran más predispuestas a adquirir nuevos ingredientes. Estas se abastecen de levaduras, enzimas y bacterias desarrolladas enteramente por los proveedores, reproduciendo el patrón tradicional de una industria "determinada por los proveedores". Son las que cuentan con la infraestructura para probar los productos que se lanzan al mercado. En ese proceso, el saber artesanal del enólogo se orienta a la selección y ensayo de las levaduras ofrecidas por los proveedores internacionales.

\subsection{Vinculación de las empresas con la infraestructura de Ciencia y Tecnología local}

Los proveedores internacionales no invierten en la generación de especies y cepas de microorganismos locales. Su estrategia se basa en la valorización de desarrollos realizados a escala mundial. Una de las principales limitaciones que presentan es que son en su mayoría cepas aisladas en otros ecosistemas, con características diferentes a los locales. Por ello, presentan desventajas frente a las cepas nativas (naturalmente presentes en el mosto) o para producir vinos con identidad regional u otras características (variedades exclusivas).

Esto ha motivado en la última década una activa estrategia de selección de levaduras nativas por parte de centros de investigación en las distintas regiones productoras (Combina, 2007). El sistema de innovación local no ha tenido las capacidades para avanzar más allá de producciones puntuales, lo que le impidió consolidar una cepa que cumpla con los requisitos de consistencia de las levaduras industriales. Algunas de ellas han intentado ser transferidas a empresas para su producción local (con bajos grados de éxito), mientras otras se encuentran en la etapa final de experimentación para la producción industrial.

La ausencia de capacidades locales para la producción de ingredientes se encuentra entre los principales limitantes para transformar las oportunidades que brinda la infraestructura local de Ciencia y Técnica en desarrollos concretos. Según los entrevistados, se trata de inversiones importantes, con barreras a la entrada para una empresa local. Ello dificulta la etapa de escalado y explica el predominio de empresas internacionales. Por otra parte, existen límites institucionales para garantizar la apropiación de las innovaciones, lo que desincentiva estos desarrollos.

Como resultado, el desarrollo de levaduras y bacterias adaptadas a condiciones locales se ve limitado, las oportunidades que brinda la infraestructura local de Ciencia y Técnica se desaprovechan y, en ciertos casos, son internalizadas por las empresas multinacionales, a partir de contratos de vinculación con laboratorios que desarrollan la cepa local y la transfieren integrándose a las redes globales de I+D, fabricación y distribución. Estos activos locales explican el despliegue en nuestro país de una estrategia de "aprovisionamiento de tecnología" (technology sourcing), por parte de filiales de empresas multinacionales de ingredientes. La superación de la incapacidad del 
sistema nacional de innovación para articular las vinculaciones entre los agentes no parece estar por el momento entre las estrategias explícitas del sector ${ }^{10}$.

\section{Conclusiones}

En los últimos quince años comienza la conformación de una industria vitivinícola global.. Como consecuencia, la industria de vinos local enfrenta un proceso de intensa reestructuración, con el desembarco de importantes jugadores internacionales en el marco de operaciones de fusiones y adquisiciones. La mayor presión competitiva da lugar a estrategias tecnológicas heterogéneas, en las que las empresas responden con distinto grado de esfuerzo tecnológico y vinculación con instituciones científicas, en función de sus capacidades tecnológicas acumuladas.

La biología molecular abre oportunidades mayores para aumentar la calidad, consistencia y diferenciación de los productos finales a partir de innovaciones en los procesos de fermentación. A partir de las entrevistas a empresas usuarias se ha constatado que las empresas muestran un alto grado de adopción de estos insumos. Los estudios de caso realizados, permitieron apreciar que las empresas locales se caracterizan por adoptar las nuevas técnicas a partir de la compra de estos ingredientes, reproduciendo el patrón de comportamiento tecnológico "determinado por los proveedores" en el cual las empresas usuarias no controlan ni la dirección ni el ritmo del cambio tecnológico.

Por su parte las capacidades tecnológicas de las empresas locales, ya sea en el desarrollo o en la adaptación de estos ingredientes, son limitadas. A excepción de las casas matrices de las grandes multinacionales, no intervienen en procesos de aprendizajes junto a los proveedores. En los casos excepcionales en los cuales existieron desarrollos puntuales, las empresas debieron recurrir a capacidades externas en microbiología, como lo evidencia una de las principales empresas locales con estrategias de innovación de productos orientadas a nichos de diferenciación. En estos casos las empresas llevan adelante acuerdos puntuales de consultoría con científicos extranjeros o con instituciones locales.

Las modalidades de interacción no involucran acuerdos formales de I\&D. Salvo un caso de desarrollo de una levadura para la variedad torrontés, las alianzas formales con proveedores no se proponen realizar desarrollos conjuntos. Sin embargo, existen aprendizajes usuarioproveedor informales como subproducto de las relaciones comerciales. La capacidad para absorber y sistematizar estos aprendizajes en competencias propias son asimétricas vis a vis los proveedores internacionales, que llevan adelante una estrategia activa de aprovisionamiento de tecnología y conocimiento sobre levaduras.

Como resultado de las limitaciones de economías de escala en activos críticos para la fabricación de levaduras y otros ingredientes, no hay un segmento de empresas locales que produzca levaduras ni bacterias adaptadas a condiciones locales. De esta forma, si bien existe un fuerte potencial para desarrollar levaduras asociado a la existencia de una infraestructura de Ciencia y Técnica con capacidades en estas áreas y con desarrollos autóctonos a escala de laboratorio, no se ha conformado un sistema nacional de innovación. La ausencia de vinculaciones proveedor-usuario en la etapa de escalado y fabricación de los ingredientes, $y$ un débil desarrollo institucional que asegure un reparto de los excedentes consistente con la innovación los institutos públicos, hace que la innovación se limite a casos puntuales. En este contexto, estos desarrollos son en gran parte impulsados a partir de contratos de vinculación con empresas multinacionales que absorben los desarrollos locales de cepas, ampliando sus bibliotecas de microorganismos en el marco de su estrategia global.

\footnotetext{
${ }^{10}$ La COVIAR (Corporación Vitivinícola Argentina) se ha propuesto formalmente avanzar en la creación de una estructura estable que pueda plantearse objetivos de largo plazo en el desarrollo de ingredientes locales, tomando como modelo el caso australiano con el financiamiento público-privado de la I+D.
} 


\section{Referencias}

ANTONELLI C., (1999) "The microdinamics of technological change" Routlege, London.

\section{ÁREA DEL VINO: www.areadelvino.com}

AYLWARD, D. (2005) “Global Landscapes: A speculative assessment of emerging organizational structures within the international wine industry", Prometheus, 23(4), December 2005, 421-36. Copyright Taylor \& Francis.

BELL M., Giuliani E.,(2007) "Catching up in the global wine industry: innovation systems, cluster knowledge networks and firm-level capabilities in Italy and Chile" International Journal of Technology and Globalisation, Volume 3, Number 2-3 p. 197 - 223

BOCCO A., Dubbini D., Rotondo S. y Yoguel G. (2007) "Reconversión y empleo en la industria del vino: Estructura productiva y dinámica del empleo en el complejo vitivinícola: un análisis del sector bodeguero nacional" $\checkmark$ Jornadas Interdisciplinarias de Estudios Agrarios y Agroindustriales, FCE-UBA.

BOCCO A., Ruiz A., Dubbini D., Vila H. y García M. (2009) "La innovación en la trama vitícola de Mendoza: los productores de uvas finas" VI Jornadas Interdisciplinarias de Estudios Agrarios y Agroindustriales, FCE-UBA, 2009.

BYÉ P. (1999), "The Food Industry: still a Craft Industry”, in P. Bye et D. Hayton, (Eds) Industrial History and Technological Development in Europe, CEE, London.

BYÉ P. et Mounier A. (198I), «L'application des biotechnologies dans l'industrie agroalimentaire : enjeux et impacts », Revue d'Economie Industrielle, $\mathrm{n}^{\circ} 18$.

CHESNAISF., (1979) L'impact des entreprises multinationales sur le potentiel scientifique et technologique national, DSTI.

COMBINA, M. (2007) “La biotecnología en enología”, Documento de Trabajo en el marco del Proyecto CEURPIP-CONICET N 54II "Economia politica de la innovacion biotecnologica. Trayectorias y demandas tecnologicas de las industrias de la alimentacion en Argentina"

DOSI G. (1984), Technical Change and Industrial Transformation, MacMillan: London et New York.
GEREFFI G. y Korzeniewicz M. (1994) (eds.), “Commodity Chains and Global Capitalism”, London: Praeger.

GROSS FUENTES M. (1999), « Trayectorias y demandas tecnológicas en el Mercosur ampliado. Vinos y uvas de mesa », PROCISUR,-BID, Montevideo.

LAVARELLO P. (200I) « Effets des Investissements directs étrangers sur les systèmes sectoriels d'innovation à l'époque de la mondialisation du capital : les cas de industries agroalimentaires en Argentine " Thèse Doctorat, Université Paris XIII, Fichiere National de Thèses, Grenoble, France.

LAVARELLO P., Filipetto S. (2010) "Industrias usuarias y proveedoras de biotecnología en Argentina: El caso de la industria vitivinícola " Documento de trabajo del Proyecto de Investigación CEUR-CONICET “Economía Política de la innovación biotecnológica. Trayectorias y demandas tecnológicas de las industrias de la alimentación en Argentina"

LUNDVALL (1992) “National Systems of innovation” Pinter, London

NICOLAS F. et Hy M. (2000), « Apprentissage technologique et innovation en agro-alimentaire », Economie Rurale, $n^{\circ} 257$, Mai-Juin.

ORGANIZACIÓN INTERNACIONAL DE LA VIÑA Y EL VINO (OIV): www.oiv.int

RASTOIN J.-L. (2000), Economie et stratégie agro-industrielle : le système agroalimentaire, Document pédagogique, Agro Montpellier, octobre.

RASTOIN J-L, Montaile E., Coelho A. (2006) « Globalisation du marché international du vin et restructuration de l'offre » Recherches en Economie et Sociologie Rurales, INRA, N 5-6 - Novembre. 
J. Technol. Manag. Innov. 20II,Volume 6, Issue 2 